\title{
Improving calving management to further enhance reproductive performance in dairy cattle
}

\author{
M. Paolucci • L. Sylla • A. Di Giambattista • \\ C. Palombi • A. Elad • G. Stradaioli • P. Pascolo • \\ M. Monaci
}

Published online: 18 May 2010

(C) Springer Science+Business Media B.V. 2010

\begin{abstract}
The aim of this study was to develop a system for the monitoring of calving to both reduce perinatal mortality and improve dairy cow fertility by preventing the majority of post-partum reproductive pathologies. Eighty dairy cows were assigned to the protocol of calving monitoring using GSM (Global System for Mobile Communications) technology. The application of GSM technology and the proper management of calving facilities comprise reliable approaches for calving assistance and improvements in reproductive efficiency and neonatal viability. Based on the results of this study, we advocate the use of GSM technology on large farms for intensive milk production.
\end{abstract}

Keywords Dairy cow $\cdot$ Calving $\cdot$ Global system for mobile communications

\author{
Abbreviations \\ GSM global system for mobile communications \\ A.P.G.A.R. Appearance, Pulse, Grimace, Activity, Respiration
}

\section{Introduction}

Traditionally, calving management was passive in spite of the fact that good calving management in cows is necessary to reduce perinatal death rates. Inadequate monitoring of pregnancies may lead to prolongation of the expulsive phase and an increase in perinatal death rates. Studies on Holstein cows have shown that calving complications cause reduced reproductive performance, resulting in a longer period between calving and conception (Dematawewa and Berger 1997). Various protocols have been proposed to determine the exact moment during which the calving process begins, including ultrasound monitoring

M. Paolucci $(\bowtie) \cdot$ L. Sylla $\cdot$ A. Di Giambattista $\cdot$ C. Palombi $\cdot$ A. Elad $\cdot$ M. Monaci

Department of Pathology, Diagnostic and Veterinary Clinics, University of Perugia, Perugia, Italy

e-mail: marco.paolucci.dvm@gmail.com

G. Stradaioli

Department of Animal Science, University of Udine, Udine, Italy

P. Pascolo

Department of Biology and Agro-Industrial Economy, University of Udine, Udine, Italy 
(Wright et al. 1988), observing changes in body temperature (Fujomoto et al. 1988; Aoki et al. 2005), analyzing blood levels of estrone sulfate and 17-ß-estradiol (Shah et al. 2007), analyzing blood levels of progesterone (Matsas et al. 1992), controlling the level of relaxation of pelvic ligaments (Dufty 1971), and determining the concentration of electrolytes present in mammary gland secretions (Bleul et al. 2006). Recently, a proposal was made regarding the use of an electronic system that once attached to the vulva, gets activated by expulsion of fetal membranes, thus, generating a radio-wave frequency that is transmitted to the global system for mobile communications (GSM). Our preliminary observations on the use of this system for dairy cows showed that the loss of calves could be reduced through emergency obstetric assistance, thus resulting in an improvement in their reproductive performance (Paolucci et al. 2008). Our main objectives were to: a) validate the calving monitoring system in dairy cows through the use of the GSM system, b) confirm the fact that this system is able to reduce stillbirth rates, and c) determine whether a large number of post-partum reproductive pathologies could be prevented through emergency obstetric intervention, thus leading to an improvement in the fertility of the herd.

\section{Materials and methods}

This study took place over a period of 12 months, and was carried out in a Holstein Friesian dairy farm located in central Italy. A total of 80 cows were selected for the protocol of calving assistance using GSM technology (Paolucci et al. 2008), specifically 40 primipara and 40 pluripara cows. Both groups were placed in the calving barn, while the control group, including 250 cows without GSM assistance, was maintained in the dry zone with permanent litter. On day $280 \pm 5$ of gestation, premonitory signs of eminent calving were evaluated. A clinical examination, along with a trans-rectal ultrasound (5 MHz), was performed to determine fetal wellness, condition of fetal membranes, as well as fetal presentation and position. After confirmation of a loosened cervical mucus plug, the transmitter was sutured to the cow vulva. The calving barn consisted of three covered lots $(4 \mathrm{~m} \times 4 \mathrm{~m})$ and a separate place for the GSM receptor and transmitter emplacement. After setting the alarm, the following parameters were examined: fetal presentation, position, postures, dimension, as well as cervical dilation. Neonatal clinical examination was then carried out using the A.P.G.A.R. score system. The reproductive parameters were extrapolated by the "Cincinnato" database, and were expressed in mean \pm SD units. The differences among the various groups was evaluated using Student's t tests $(\mathrm{P}<0.05)$.

\section{Results}

Calving was observed $36 \pm 8 \mathrm{~h}$ after the application of the GSM device mainly in the night time (Fig. 1). Approximately $15 \pm 5 \mathrm{~min}$ after setting the alarm, $62.5 \%$ of the fetuses presented with their front limbs already out of the vulvar outlet. Among the primipara cows, $38 \%$ presented dystocia (33\% for abnormal postures and 5\% for fetal macrosomy), whereas in the pluripara group $21 \%$ presented dystocia, all of fetal origin. The mean A.P.G.A.R. score was 8.5. Furthermore, there was a significant reduction in both puerperal and neonatal pathologies, both in the primipara and pluripara groups (Table 1). In the control group, $17.8 \%$ and $21.3 \%$ of pluripara and primipara cows, respectively, presented stillbirth, while the experimental group did not present any occurrence of stillbirth. The rate of puerperal abnormalities was higher in the control group with $17.6 \%$ of pluripara and $29.7 \%$ of primipara cows being affected by endometritis. Comparatively, only $2.5 \%$ of the monitored 


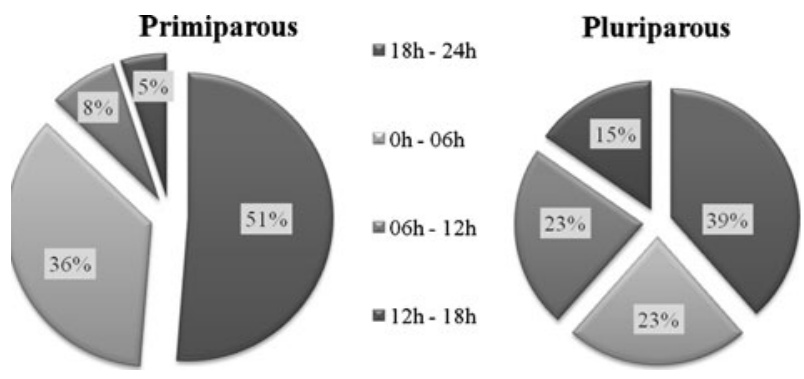

Fig. 1 Calving distribution of pluripara and primipara cows monitored with the GSM technology

group was affected. The incidence of fetal membrane retention in the control group was $15.1 \%$ and $25.1 \%$ for pluripara and primipara cows, respectively. Conversely, fetal membrane expulsion occurred spontaneously in the monitored group. The calving-toconception interval reduced significantly in the monitored primipara and pluripara cows as compared to the control group, 99.6 vs. 199.6 days and 106.9 vs. 148.0 days, respectively. The same trend was observed for the mean number of inseminations per conception in the two groups for the primipara (1.7 vs. 3.8$)$ and the pluripara cows (2.0 vs. 3.1).

\section{Discussion}

The application of GSM technology, along with good management of the calving barn, proved to be a reliable tool in dairy cow calving management and assistance. The results demonstrated that adequate and ready obstetric intervention can prevent various pathologies connected to stillbirth, such as post-partum uterine infections and reduced perinatal deaths, as well as a clear improvement in reproductive performance. In spite of the decreased number of clinical observations, such results are encouraging. However, the main disadvantage of this procedure is related to its high cost in term of purchase, maintenance, and installation. Currently, we are testing alternative systems that require lower costs in terms of purchase, installation, and maintenance for the milk industry.

Table 1 Calving to conception interval, number of inseminations per conception, and postpartum diseases

\begin{tabular}{|c|c|c|c|c|}
\hline & \multicolumn{2}{|l|}{ Monitored group } & \multicolumn{2}{|l|}{ Control group } \\
\hline & pluripara $n=40$ & primipara $n=40$ & pluripara $n=119$ & primipara $n=131$ \\
\hline A & & & $9(7.5 \%)$ & $4(3.0 \%)$ \\
\hline SB & & & $21(17.6 \%)$ & $28(21.3 \%)$ \\
\hline $\mathrm{E}$ & $1(2.5 \%)$ & $1(2.5 \%)$ & $21(17.6 \%)$ & $39(29.7 \%)$ \\
\hline FMR & & & $18(15.1 \%)$ & $33(25.1 \%)$ \\
\hline UP & $1(2.5 \%)$ & & $2(1.6 \%)$ & $3(2.2 \%)$ \\
\hline MF & & & $8(6.7 \%)$ & \\
\hline CCI & $99.6 \pm 44.9 *$ & $106.9 \pm 48.1^{*}$ & $199.6 \pm 23.9 *$ & $148.0 \pm 34.2 *$ \\
\hline NIC & $1.7 \pm 1.3^{*}$ & $2.0 \pm 0.9^{*}$ & $3.8 \pm 1.6^{*}$ & $3.1 \pm 1.2 *$ \\
\hline
\end{tabular}

A: abortion; SB:= stillbirth; E: endometritis; FMR: fetal membrane retention; UP: uterine prolapse; MF: milk fever; CCI: calving to conception interval; NIC: number of insemination per conception

$\mathrm{P}<0.05$ monitored versus control group 


\section{References}

Aoki M, Kimura K, Suzuki O (2005) Predicting time of parturition from changing vaginal temperature measured by data-logging apparatus in beef cows with twin fetuses. Animal Repro Sci 86:1-12

Bleul U, Spirig S, Hassig M, Kahn W (2006). Electrolytes in bovine prepartum mammary secretions and their usefulness for predicting parturition. J Dairy Sci 89:3059-3065

Dematawewa CMB and Berger PJ (1997) Effect of dystocia on yield, fertility, and cow losses and an economic evaluation of dystocia scores for Holsteins. J Dairy Sci 80:754-761

Dufty JH (1971) Determination of the onset of parturition in Hereford cattle. Aust Vet J 47:77-82

Fujomoto Y, Kimura E, Sawada T, Ishikawa M, Matsunaga H, Mori J (1988) Change in rectal temperature, and heart and respiration rate of dairy cows before parturition. Jpn J Zootech Sci 59:301-305

Matsas DJ, Nebel RL, Pelzer KD (1992) Evaluation of an on-farm blood progesterone test for predicting the day of parturition in cattle. Theriogenol 37(4):859-868

Paolucci M, Di Giambattista A, Sylla L, Menichelli M, Banchio A, Monaci M (2008) Predicting time of parturition in Holstein Friesian cows by using C6 Birth Control ${ }^{\mathbb{R}}$. Proc $16^{\text {th }}$ Intl Congress Animal Repro Suppl 43(3):57-58

Shah KD, Nakao T, Kubota H (2007) Peripartum changes in plasma estrone sulphate and estradiol-17ß profiles associated with and without the retention of fetal membranes in holstein-friesian cattle. J Reprod Dev 53(2):279-288

Wright IA, White IR, Russel AJF, Whyte TK, McBean AJ (1988) Prediction of calving date in beef cows by real-time ultrasonic scanning. Vet Rec 123(9):228-229 